\title{
Characteristic study on the chemical components of Korean curved ginseng products
}

\author{
Chang-Won Cho, Young-Chan Kim, Jin-Hee Kang, Young Kyoung Rhee, Sang Yoon Choi, \\ Kyung-Tack Kim, Young-Chul Lee, and Hee-Do Hong*
}

Korea Food Research Institute, Seongnam 463-420, Korea

Dried ginseng (DG) is in fact the representing ginseng product in the worldwide market. Although it is made in various packages depending on the processing method, size and age of DG, basic scientific data reporting the chemical components are limited. In this study, 4-year-old curved ginseng (CG), one of the domestic DG products, was selected for further investigation. Eighty-six samples of 30 and 50 piece-grade CG, which are the most widely distributed in the market, were collected for 5 yr. Their major components, such as moisture, total sugar, acidic polysaccharides, total phenolic compounds, and saponins, were analyzed to figure out the standard quality characteristics. The moisture content of all CG samples was less than $15 \%$. The total water-soluble sugar contents were $22.9 \%$ to $47.8 \%$ and $23.2 \%$ to $49.5 \%$ in the 30 and 50 piece-grade CG, respectively. The acidic polysaccharide contents were $3.6 \%$ to $6.7 \%$ and $2.9 \%$ to $6.9 \%$ in the 30 and 50 piece-grade CG, respectively. The total phenolic compound content was $0.4 \%$ to $0.5 \%$ in CG, regardless of the piece-grade. The crude saponin content, which represents the active component of ginseng, was over $2 \%$ in all samples. In 30 piece-grade CG samples, the contents of major ginsenosides, Rb1, Rf, and Rg1, were 2.2 to $4.7 \mathrm{mg} / \mathrm{g}, 0.4$ to $1.3 \mathrm{mg} / \mathrm{g}$, and 1.6 to $4.0 \mathrm{mg} / \mathrm{g}$, respectively. The ginsenoside contents in 50 piece-grade CG samples were 2.1 to $3.9 \mathrm{mg} / \mathrm{g}$ (Rb1), 0.5 to $1.2 \mathrm{mg} / \mathrm{g}$ (Rf), and 1.3 to $3.4 \mathrm{mg} / \mathrm{g}$ (Rg1). Overall, since there were relatively high standard deviation and coefficient of variation in all the chemical component contents that were assessed, we found some difficulties in showing the CG standard chemical component characteristics by average, standard deviation, and other statistical analysis factors.

Keywords: Panax ginseng, Korean curved ginseng, Chemical components, Statistic analysis, Standardization

\section{INTRODUCTION}

Korean ginseng (Panax ginseng Meyer) is a perennial plant in the family Araliaceae and a medicinal herb cultivated primarily in the Northeast Asia, including Korea. Dried ginseng (DG) and red ginseng (RG) products have been consumed as important functional foods, constituting more than $50 \%$ of the domestic health/functional foods market. Saponin, a major component of Korean ginseng, was first highlighted as an active component of ginseng in 1957 by Brekhman of Russia, and its structure was elucidated and named as ginsenoside by the

(c) This is an Open Access article distributed under the terms of the Creative Commons Attribution Non-Commercial License (http://creativecommons.org/licenses/by-nc/3.0/) which permits unrestricted non-commercial use, distribution, and reproduction in any medium, provided the original work is properly cited.
Shibata research group of Japan [1]. Ginsenoside has been used as the primary substance for establishing the quality specifications of ginseng. Ginsenoside has also been determined to be the active ingredient that confers a wide range of beneficial health effects of ginseng, such as anticancer, antidiabetic, antineurodegenerative, antiinflammatory actions, hepatic function improvement, and maintaining homeostasis in the body [2-6]. Korean ginseng contains various functional components, in addition to ginsenoside, such as phenolic compounds with

Editied by Sang-Kook Lee, Seoul National University, Korea

Received 08 Jun. 2012, Revised 02 Jan. 2013, Accepted 18 Feb. 2013

*Corresponding author

E-mail: honghd@kfri.re.kr

Tel: +82-31-780-9285, Fax: +82-31-709-9876 
anti-oxidative activity, compounds with demonstrated cytotoxicity to cancer cells, such as polyacetylene, and sesquiterpene, which is an essential oil. Meanwhile, current studies are actively investigating polysaccharides with respect to immune-related functions [7]. Studies on the functionality of major active components such as ginsenoside and on the improvement of substance content and functionality through puffing, acid treatment, and high heat treatment have been vigorously conducted. However, these studies have primarily focused on RG and its specific substances [8-10].

Currently, ginseng products distributed in the domestic market can be largely classified as fresh ginseng and processed products, RG and DG. DG is a ginseng product that has not been cooked but is dried in sunlight, by hot winds or other methods. Considering the fact that most foreign-made ginseng that is sold in the international market resembles DG, studies should be conducted on the functionality and utilization of DG. For that purpose, the standardization of quality and specification of domestic DG products were necessary. Several previous studies have reported on the quality and physicochemical properties of DG $[11,12]$. However, it was difficult to represent the physicochemical quality characteristics of DG products because most of them were one-time studies, or the range of sample selection and quality evaluation parameters was narrow. Presently, DG is classified based on the age (i.e., 4-, 5-, and 6-year-old root) and by shape (i.e., straight ginseng [SG], curved ginseng [CG], and half$\mathrm{CG})$. SG retains the original shape with skin, but $\mathrm{CG}$ is produced by peeling skin and rolling the entire length of the ginseng root into a round shape during drying. Commercial DG is also classified by the quality-grade (i.e., 1st, 2nd, and 3rd grade) depending on the morphological quality. In addition, the number of ginseng roots per package has been counted and then classified into 30 and 50 piece-grade when 30 and 50 pieces of ginseng root are counted per $300 \mathrm{~g}$ of package, respectively. DG is sold in packages in various pieces ranging from 5 to 75 piecegrade. Until now, studies on the chemical properties by quality-grade and piece-grade of DG are not available. Therefore, this study was conducted to provide the basic data for standardization of quality characteristics by piece-grade and for establishing new grading criteria for DG.

In summary, we selected samples of 30 and 50 piecegrade from the 1st quality-grade CG (4-year-old) products among the DG products that are the most widely distributed and sold in Korean DG markets. Eightysix samples were collected for $5 \mathrm{yr}$, and then moisture content, water-saturated butanol extract (crude saponin) content, ginsenoside content, total phenolic compounds, and acidic polysaccharides content were measured and statistically analyzed.

\section{MATERIALS AND METHODS}

\section{Ginseng samples}

Four-year-old CG of the 1st quality-grade in 30 and 50 piece-grade packages were selected as the target samples among major DG products. The CG was produced from 2006 to 2010. Eighty-six products (43 products for each piece-grade), with 5 to 10 products per year, were collected from major domestic DG markets, such as Gyeongdong Market (Seoul, Korea) and Geumsan Market (Geumsan, Korea) and used as samples for chemical components analysis. All of the chemical components analyses were performed every year within $1 \mathrm{mo}$ after sample preparation. The samples were evenly pulverized to 60-mesh size prior to testing. All samples of CG products were finished products, and only products that passed the quality test by the inspection office of the National Agricultural Cooperative Federation (Geumsan, Korea) or manufacturer were used for our analysis.

\section{Water content}

The water content was determined according to the AOAC (Association of Official Agricultural Chemists) official method 925.45 [13].

\section{Water soluble total sugar content}

The total sugar content was quantified by a phenolsulfuric acid method using glucose as a reference [14].

\section{Acidic polysaccharide content}

The acidic polysaccharide content was quantified by a carbazole-sulfuric acid method using $\beta$-D-galacturonic acid as a reference [15].

\section{Phenolic compound content}

The total phenolic compound content was measured according to the Folin-Ciocalteu method using gallic acid as a reference [16].

\section{Crude saponin content}

The crude saponin content was determined according to the CODEX official method [17].

\section{HPLC analysis of ginsenosides content}

The ginsenosides content was measured using HPLC 
according to the previous method [18].

\section{Statistical analysis}

Basic statistical analysis was performed for the chemical analysis results between $\mathrm{CG}$ products and among the piece-grade for each sample. The mean, standard deviation, minimum, maximum, and coefficients of variation $(\mathrm{CV}, \%)$ were calculated.

\section{RESULTS AND DISCUSSION}

\section{Moisture content}

The results of the moisture content analysis of CG products by piece-grade are shown in Table 1 . The moisture content of 30 piece-grade CG was $7.4 \%$ to $12.9 \%$ and that of 50 piece-grade was $6.6 \%$ to $12.8 \%$. The average moisture contents were $10.4 \%$ and $10.2 \%$ for 30 and 50 piece-grade $\mathrm{CG}$, respectively. The CVs, which describe the difference among individuals within the same CG products, were $13.8 \%$ and $15.4 \%$. Such a wide difference among individuals is thought to be associated with the differences in drying state during the manufacturing process and of natural drying during the distribution period after manufacturing. The overall moisture content of all CG products did not exceed $15 \%$, which is within the inspection criterion that is defined in the domestic ginseng-related regulations [19].

\section{Water soluble sugar and acidic polysaccharide contents}

The total water-soluble sugar and acidic polysaccharides content analysis of CG products by piece-grade are shown in Tables 2 and 3. The total water-soluble sugar in 30 piece-grade was $22.9 \%$ to $47.8 \%$ and 50 piecegrade was $23.2 \%$ to $49.5 \%$. Total water-soluble sugar content was not significantly different by piece-grade, as the overall mean was $36.5 \%$. The CVs for the total water-soluble sugar were $17.2 \%$ and $16.1 \%$ for 30 and 50 piece-grade, respectively. These results demonstrate that the difference in total water-soluble sugar among products was relatively high in all CG products that were analyzed.

With regard to ginseng polysaccharides, particularly acidic polysaccharides, many studies conducted in the past revealed their positive effect on various physiological activities, such as immune function improvement, anti-tumor, anti-ulcer, and anti-diabetic activities [20,21]. For acidic polysaccharide content by piece-grade, 30 piece-grade possessed $3.6 \%$ to $6.7 \%$, and 50 piece-grade had $2.9 \%$ to $6.9 \%$. The mean acidic polysaccharide
Table 1. Moisture content of Korean curved ginseng products

\begin{tabular}{lccc}
\hline & \multicolumn{3}{c}{ Moisture content (\%) } \\
\cline { 2 - 4 } & $\begin{array}{l}30 \text { Piece-grade }^{1)} \\
(n=43)\end{array}$ & $\begin{array}{c}\text { Piece-grade } \\
(n=43)\end{array}$ & $\begin{array}{c}\text { Total } \\
(n=86)\end{array}$ \\
\hline Mean & 10.4 & 10.2 & 10.3 \\
$\mathrm{SD}$ & 1.4 & 1.6 & 1.5 \\
Maximum & 12.9 & 12.8 & 12.9 \\
Minimum & 7.4 & 6.6 & 6.6 \\
Coefficient of variance $(\%)^{2)}$ & 13.8 & 15.4 & 14.5 \\
\hline${ }^{1)}$ Piece-grade: number of pieces per $300 \mathrm{~g}$ package for each curved \\
ginseng products.
\end{tabular}

Table 2. Total sugar content of Korean curved ginseng products

\begin{tabular}{lccc}
\hline & \multicolumn{3}{c}{ Total sugar content (\%) } \\
\cline { 2 - 4 } & $\begin{array}{c}\text { 30 Piece-grade } \\
(n=43)\end{array}$ & $\begin{array}{c}\text { 50 Piece-grade } \\
(n=43)\end{array}$ & $\begin{array}{c}\text { Total } \\
(n=86)\end{array}$ \\
\hline Mean & 36.5 & 36.4 & 36.5 \\
SD & 6.3 & 5.9 & 6.0 \\
Maximum & 47.8 & 49.5 & 49.5 \\
Minimum & 22.9 & 23.2 & 22.9 \\
Coefficient of variance $(\%)^{2)}$ & 17.2 & 16.1 & 16.6
\end{tabular}

${ }^{1)}$ Piece-grade: number of pieces per $300 \mathrm{~g}$ package for each curved ginseng products.

${ }^{2)}(\mathrm{SD} /$ mean $) \times 100$.

Table 3. Acidic polysaccharide content of Korean curved ginseng products

\begin{tabular}{lccc} 
& \multicolumn{3}{c}{ Acidic polysaccharide content $(\%)$} \\
\cline { 2 - 4 } & $\begin{array}{c}30 \text { Piece-grade } \\
(n=43)\end{array}$ & $\begin{array}{c}\text { 50 Piece-grade } \\
(n=43)\end{array}$ & $\begin{array}{c}\text { Total } \\
(n=86)\end{array}$ \\
\hline Mean & 5.2 & 5.4 & 5.3 \\
SD & 0.9 & 1.0 & 1.0 \\
Maximum & 6.7 & 6.9 & 6.9 \\
Minimum & 3.6 & 2.9 & 2.9 \\
Coefficient of variance $(\%)^{2)}$ & 17.1 & 18.8 & 18.0 \\
\hline
\end{tabular}

${ }^{1)}$ Piece-grade: number of pieces per $300 \mathrm{~g}$ package for each curved ginseng products.

(SD/mean) $\times 100$.

contents of 30 and 50 piece-grade were $5.2 \%$ and $5.4 \%$, respectively. This content was not significantly different from the previously reported value of $4.9 \%$ acidic polysaccharides in DG, as determined by Nam [22]. The CVs for 30 and 50 piece-grade were $17.1 \%$ and $18.8 \%$, respectively.

\section{Phenolic compound content}

The result of the phenolic compound content analysis of CG products by piece-grade is shown in Table 4 . The total phenolic compound content was $0.4 \%$ to $0.5 \%$ and 
Table 4. Total phenolic compound content of Korean curved ginseng products

\begin{tabular}{lccc}
\hline & \multicolumn{3}{c}{ Total phenolic compound content (\%) } \\
\cline { 2 - 4 } & $\begin{array}{c}30 \text { Piece-grade }^{\mathrm{l})} \\
(n=43)\end{array}$ & $\begin{array}{c}\text { Piece-grade } \\
(n=43)\end{array}$ & $\begin{array}{c}\text { Total } \\
(n=86)\end{array}$ \\
\hline Mean & 0.4 & 0.4 & 0.4 \\
SD & 0.0 & 0.0 & 0.0 \\
Maximum & 0.5 & 0.5 & 0.5 \\
Minimum & 0.4 & 0.4 & 0.4 \\
Coefficient of variance $(\%)^{2)}$ & 9.3 & 10.4 & 9.8
\end{tabular}

${ }^{1)}$ Piece-grade: number of pieces per $300 \mathrm{~g}$ package for each curved ginseng products.

${ }^{2)}(\mathrm{SD} /$ mean $) \times 100$.

the mean was $0.4 \%$, regardless of the piece-grade. The CV was approximately $10 \%$ for each piece-grade. Phenolic compounds present in ginseng are the major active components that confer its anti-oxidative activity. Choi et al. [23] reported that phenolic compounds in Korean white ginseng existed in the free, esterified and insolublebound form, at a relative quantity of $0.4 \%, 0.2 \%$, and $0.1 \%$, respectively.

\section{Crude saponin and ginsenoside contents}

The results of the crude saponin (water saturated nbutanol extracts) and ginsenosides content analysis of CG products by piece-grade are shown in Tables 5 and 6. The crude saponin contents in 30 and 50 piece-grade were $2.3 \%$ to $4.4 \%$ and $2.2 \%$ to $4.1 \%$, respectively, and the mean were $3.3 \%$ and $3.0 \%$, respectively. In general, the crude saponin content was over $2 \%$, which is within the quality criteria for crude saponin currently defined in the domestic ginseng-related regulations [19]. The minimum value, including the experimental errors, was considered when determining our data's compliance with the domestic regulations. Studies from Gil [12] reported crude saponin content ranging from of $2.8 \%$ to $4.3 \%$, by piece-grade of DG in the domestic markets.

Ginsenoside, which is known as the major active component of ginseng, is mainly divided into 3 types, protopanaxadiol, protopanaxatriol, and oleanane, according to its molecular structure. To date, approximately 30 types of ginsenosides have been separated and identified from raw and processed ginsengs [7]. In the case of DG, which is a simply dried ginseng product, $\mathrm{Rb} 1, \mathrm{Rb} 2, \mathrm{Rc}$, $\mathrm{Rd}, \mathrm{Re}, \mathrm{Rf}$, and $\mathrm{Rg} 1$ are the primary ginsenosides components that are detected. In domestic health functional food law, over 0.8 to $34.0 \mathrm{mg} / \mathrm{g}$ of Rb1 and Rg1 contents are suggested as the quality criteria for ginseng powder [24]. Thus, the contents of Rb1, Rg1, and Rf, the unique
Table 5. Crude saponin content of Korean curved ginseng products

\begin{tabular}{lccc}
\hline & \multicolumn{3}{c}{ Crude saponin content (\%) } \\
\cline { 2 - 4 } & $\begin{array}{c}30 \text { Piece-grade }^{1)} \\
(n=43)\end{array}$ & $\begin{array}{c}\text { Piece-grade } \\
(n=43)\end{array}$ & $\begin{array}{c}\text { Total } \\
(n=86)\end{array}$ \\
\hline Mean & 3.3 & 3.0 & 3.2 \\
SD & 0.6 & 0.5 & 0.6 \\
Maximum & 4.4 & 4.1 & 4.4 \\
Minimum & 2.3 & 2.2 & 2.2 \\
Coefficient of variance $(\%)^{2)}$ & 17.2 & 17.0 & 17.5 \\
\hline
\end{tabular}

${ }^{1)}$ Piece-grade: number of pieces per $300 \mathrm{~g}$ package for each curved ginseng products.

${ }^{2)}(\mathrm{SD} / \mathrm{mean}) \times 100$.

ginsenoside of Korean ginseng, were analyzed in this study. The mean contents of Rb1, Rf, and Rg1 in 30 piece-grade CG were $3.1,0.8$, and $2.7 \mathrm{mg} / \mathrm{g}$, respectively, and for 50 piece-grade, the mean contents were $2.8,0.7$, and $2.4 \mathrm{mg} / \mathrm{g}$, respectively. The $\mathrm{CV}$, which represents the difference among individuals by piece-grade was $16.3 \%$ to $32.1 \%$. Currently, the regulatory specifications for the distribution and quality control of DG are defined by visual and physical attributes, such as weight, color, and other properties. In the case of chemical composition, only moisture and the maximum content of harmful components such as arsenic, heavy metals, and foreign objects and the minimum content criteria of crude saponin are applied. The previously reported study on the quality characteristics of DG [12] and the subsequent study on the physicochemical characteristics by size and age [11] and on the changes in physicochemical characteristics of DG by processing treatment were primarily focused on the content of saponin or ginsenosides $[25,26]$. However, it is thought that most studies on physicochemical properties or component characteristics of DG did not use a variety of DG types and piece-grades. Thus, these studies could not reflect the considerable quality characteristics of DG samples.

In our study, we tried to present the standard component characteristics of CG products, along with the standardization study on morphological characteristics that were previously examined [27]. Eighty-six CG samples by piece-grade were collected for 5 years, and the major chemical components were analyzed and statistically compared. Overall, since there were relatively high standard deviation and $\mathrm{CV}$ in all the chemical component contents that were assessed, we found some difficulties in showing the CG standard chemical component characteristics by average, standard deviation, and other statistical analysis factors. In addition, the result of comparing 
Cho et al. Chemical components of Korean curved ginseng

Table 6. Ginsenoside composition of Korean curved ginseng products

\begin{tabular}{|c|c|c|c|c|c|c|c|c|c|}
\hline & \multicolumn{9}{|c|}{ Ginsenoside content $(\mathrm{mg} / \mathrm{g})$} \\
\hline & \multicolumn{3}{|c|}{30 Piece-grade ${ }^{1)}(n=43)$} & \multicolumn{3}{|c|}{50 Piece-grade $(n=43)$} & \multicolumn{3}{|c|}{ Total $(n=86)$} \\
\hline & $\mathrm{Rb} 1$ & $\mathrm{Rf}$ & Rg1 & $\mathrm{Rb} 1$ & $\mathrm{Rf}$ & $\operatorname{Rg} 1$ & $\mathrm{Rb} 1$ & $\mathrm{Rf}$ & $\operatorname{Rg} 1$ \\
\hline Mean & 3.1 & 0.8 & 2.7 & 2.8 & 0.7 & 2.4 & 3.0 & 0.8 & 2.5 \\
\hline SD & 0.6 & 0.3 & 0.6 & 0.5 & 0.2 & 0.4 & 0.6 & 0.2 & 0.5 \\
\hline Maximum & 4.7 & 1.3 & 4.0 & 3.9 & 1.2 & 3.4 & 4.7 & 1.3 & 4.0 \\
\hline Minimum & 2.2 & 0.4 & 1.6 & 2.1 & 0.5 & 1.3 & 2.1 & 0.4 & 1.3 \\
\hline Coefficient of variance $(\%)^{2)}$ & 20.0 & 32.1 & 20.3 & 16.3 & 27.7 & 18.5 & 19.2 & 30.1 & 20.6 \\
\hline
\end{tabular}

${ }^{1)}$ Piece-grade: number of pieces per $300 \mathrm{~g}$ package for each curved ginseng products.

${ }^{2)}(\mathrm{SD} /$ mean $) \times 100$.

CG products by piece-grade, chemical component characteristics did not show significant differences. Also, it is difficult to use the CG chemical contents as the graded product guideline considering the previously addressed high individual difference and $\mathrm{CV}$. In order to determine the exact standard quality characteristics of Korean CG, it has become necessary to collect large quantities of samples and perform constant analysis in the long term. Most of all, rather than establishing chemical products by various piece-grade, it has been considered that it is necessary to establish the standard product characteristics of all Korean CG products of all piece-grade. The results of this study are useful as a basic data set for selection of standard samples and for comparison of quality characteristics between products for the verification of the efficacy of DG.

\section{REFERENCES}

1. Shibata S, Tanaka O, Sato M, Tsushima S. On genuine sapogenin of ginseng. Tetrahedron Lett 1963;12:795-800.

2. Bachran C, Bachran S, Sutherland M, Bachran D, Fuchs H. Saponins in tumor therapy. Mini Rev Med Chem 2008;8:575-584.

3. Xie JT, Mchendale S, Yuan CS. Ginseng and diabetes. Am J Chin Med 2005;33:397-404.

4. Cho IH. Effects of Panax ginseng in neurodegenerative diseases. J Ginseng Res 2012;36:342-353.

5. Fujimoto K, Sakata T, Ishimaru T, Etou H, Ookuma K, Kurokawa M, Machidori H. Attenuation of anorexia induced by heat or surgery during sustained administration of ginsenoside $\operatorname{Rg} 1$ into rat third ventricle. Psychopharmacology (Berl) 1989;99:257-260.

6. Sakato T, Etou H, Fujimoto K, Ookuma K, Hayachi T, Arichi S. Central effects of ginsenosides on the feeding behavior and response to stress in rats. Korean J Ginseng Sci 1987;11:164-172.
7. Park JD. Recent studies on the chemical constituents of Korean ginseng (Panax ginseng C. A. Meyer). Korean J Ginseng Sci 1996;20:389-415.

8. Kim ST, Jang JH, Kwon JH, Moon KD. Changes in the chemical components of red and white ginseng after puffing. Korean J Food Preserv 2009;16:355-361.

9. Kwak YS, Choi KH, Kyung JS, Won JY, Rhee MH, Lee JG, Hwang MS, Kim SC, Park CK, Song KB et al. Effects of high temperature heating on the some physicochemical properties of Korean red ginseng (Panax ginseng C. A. Meyer) water extract. J Ginseng Res 2008;32:120-126.

10. Kim MH, Hong HD, Kim YC, Rhee YK, Kim K, Rho J. Ginsenoside changes in red ginseng manufactured by acid impregnation treatment. J Ginseng Res 2010;34:93-97.

11. Hwang J, Ha J, Hawer W, Nahmgung B, Lee B. Ginsenoside contents of Korean white ginseng taegeuk ginseng with various sizes and cultivation years. Korean J Food Sci Technol 2005;37:508-512.

12. Gil B. A survey on the quality characteristics of dried ginseng products. Korean J Food Sci Technol 2003;35:10031006.

13. Horwitz W, Latimer GW. Official methods of analysis of AOAC International. 18th ed. Gaithersburg: AOAC International, 2005.

14. Dubois M, Gilles KA, Hamilton JK, Robers PA, Smith F. Colorimetric method for determination of sugar and related substances. Anal Chem 1956;28:350-356.

15. Do JH, Lee HO, Lee SK, Jang JK, Lee SD, Sung HS. Colorimetric determination of acidic polysaccharide from Panax ginseng, its extraction condition and stability. Korean J Ginseng Sci 1993;17:139-144.

16. Singleton VL, Rossi JA. Colorimetry of total phenolics with phosphomolybdic-phosphotungstic acid reagents. Am J Enol Vitic 1965;16:144-158.

17. CODEX STAN 295R-2009 Regional standard for ginseng products (Asian). Annex B. Determination of watersaturated 1-butanol extracts (2009). 
18. Hong HD, Sim EM, Kim KT, Rho JH, Rhee YK, Cho $\mathrm{CW}$. Comparison of preparation methods for quantification of ginsenosides in raw Korean ginseng. Food Sci Biotechnol 2009;18:565-569.

19. Law for Ginseng Industry, No. 11690 (Mar 23, 2011).

20. Park CK, Jeon BS, Yang JW. The chemical components of Korean ginseng. Food Ind Nutr 2003;8:10-23.

21. Konno C, Sugiyama K, Kano M, Takahashi M, Hikino H. Isolation and hypoglycaemic activity of panaxans $\mathrm{A}, \mathrm{B}$, C, D and E, glycans of Panax ginseng roots. Planta Med 1984;50:434-436.

22. Nam KY. The comparative understanding between red ginseng and white ginsengs, processed ginsengs (Panax ginseng C.A. Meyer). J Ginseng Res 2005;29:1-18.

23. Choi CS, Kim KI, Hong HD, Choi SY, Lee YC, Kim KT,
Rho J, Kim SS, Kim YC. Phenolic acid composition and antioxidative activity of white ginseng (Panax ginseng, C. A. Meyer). J Ginseng Res 2006;30:23-30.

24. Law for Health Functional Foods, No. 11690 (Mar 23, 2013).

25. Choi JE, Nam KY, Li X, Kim HH, Cho HS, Hwang KB, Ko SK. Changes of surface color formation and constituents of white ginseng prepared with peeling by using barker. Korean J Crop Sci 2008;53:369-375.

26. Lim SI, Cho CW, Choi UK, Kim YC. Antioxidant activity and ginsenoside pattern of fermented white ginseng. J Ginseng Res 2010;34:168-174.

27. Hong HD, Cho CW, Kim YC, Kim EY, Rhee YK, Rho JH, Choi SH. Morphological characteristics of Korean dried ginseng products. J Ginseng Res 2012;36:314-321. 